\title{
Status and functioning of distance education in Bhutan: an evaluative study
}

\author{
Prakash Chandra Jena \\ School of Education and Humanities, Lovely Professional University, Phagwara, \\ Punjab 144411, India \\ E-mail address: drpcjena@gmail.com
}

\begin{abstract}
Bhutan is a small, landlocked country in southern Asia, between China and India. Its population is 634,982 , and it covers 38,394 square kilometers. It has one of the world's smallest and least developed economies. Agriculture, forestry, and hydroelectric power provide the main sources of income for $90 \%$ of the population. International agencies are currently supporting a number of educational, social, and environmental programs. In 2003, the higher education sector in Bhutan was reorganized through the creation of the Royal University of Bhutan bringing together eight higher education institutes and two teacher education institutions, including the National Institute of Education (NIE) in Samtse, which is in the southern border of Bhutan with India. Recently, the NIE was renamed as Samtse College of Education and the Paro College of Education in the west. The Royal University of Bhutan, founded on $2^{\text {nd }}$ June, 2003 by a royal decree is the national university system of Bhutan. It was established to consolidate the management of tertiary education in Bhutan. It is a decentralized university with 10 constituent colleges spread across the kingdom. The present study focuses the growth and functioning of distance education in Bhutan.
\end{abstract}

Keywords: Distance Education; Royal University; National Institute of Education

\section{INTRODUCTION}

The phenomenon of globalization has become deep rooted in all fields including the field of education across the globe. As education is the fundamental right for the citizens, it is necessary to improve education quality and governance. The quality of education is directly related to the quality of instruction in the class rooms. It is the teacher who is a crucial factor in implementing all educational reforms at the grass roots level. Education plays a pivotal role in the modern society. The economic, social and cultural advancement of a country depends on the educational system. Education is a comprehensive and complex process bringing about not only change in knowledge and skills but also changes in attitude, behavior and need. It also aims at an integration of these aspects to help an individual develop as totality. Education enables an individual to live his life efficiently and successfully by relating and utilizing his abilities and potentialities.

The $21^{\text {st }}$ century is characterized by the evolving of multi cultureless due to industrialization, urbanization, globalization and disintegration in the normal life. Since 
education is viewed as an instrument to develop the cognitive qualities, tolerance and understanding of people, it should prepare the younger generations to understand and face the realities of globalization. This involves the process of identifying the strengths and potential of each child and assisting him to develop that potential to the fullest and empowering him to achieve human excellence. Education in the general sense is any act or experience that has a formative effect on the mind, character, or physical ability of an individual. In its technical sense, education is the process by which society deliberately transmits its accumulated knowledge, skills, and values from one generation to another. An educated person refers to a person that has access to optimal states of mind regardless of the situation they are in. That person is able to perceive accurately, think clearly and act effectively to achieve self-selected goals and aspirations. A controversial topic in higher education resolves around the enormous growth of distance education and today the distance education or distance learning is not a future possibility for which education must prepare. It's a current reality creating opportunities and challenges for educational institutions. It's also a realty offering students expanded choices in where, when, how and from whom they learn. Interest in the concept of distance education has graved the attention of university and colleges, faculty, and other professionals all over the world.

\section{EDUCATION IN BHUTAN}

Until the 1950s, education in Bhutan was mainly monastic. Literacy was confined to the monasteries, and many eminent Bhutanese scholars traveled to Tibet to study Buddhist scriptures. In the 1950s, under the second king, His Majesty Jigme Wangchuck, Bhutan opened its first secular schools, with both the curriculum and the medium of instruction (Hindi) borrowed from India. But it was in the 1960s, under the third king, His Majesty Jigme Dorji Wangchuck, that Bhutan began to build its education system in earnest. Realizing that the small, isolated country needed to be able to communicate with the rest of the world, the third king made English the language of instruction. This laid the foundations for the network of primary, secondary and post-secondary institutions spread across Bhutan today.

Since then, education has contributed significantly to Bhutan's rapid development, in line with its philosophy of "Gross National Happiness." Being educated in English has enabled Bhutanese students to study in all parts of the world, earning degrees in everything from accounting to medicine to visual arts, and to return to Bhutan to apply their knowledge and skills. Today, the education system includes formal, non-formal, and monastic schools. Enrolment in the formal system begins at age six, but students can apply to the monastic schools at any age. The non-formal centers provide basic literacy skills for all ages. The government provides free education to all students until Grade 10 and scholarships to students who meet the requirements for higher and professional studies. According to the general statistics 2008 produced by the Ministry of Education, there are 552 formal schools and institutions, 391 monastic schools and 747 non- formal education centers in Bhutan. In the formal schools, girls make up $49.5 \%$ enrolment, although it is as high as $52 \%$ in urban areas and a few districts. Approximately $23 \%$ of primary students, $33 \%$ of middle school students, and $60 \%$ of higher secondary students enjoy free boarding facilities. Dzongkha is the national language of Bhutan. It has some similarity to Tibetan in speaking, while the alphabets are exactly same as Tibetan (but uses different style of scripts). It is also taught in schools and all students can speak Dzongkha and English. Although Dzongkha is a major subject in schools, English has taken precedence over Dzongkha in terms of students' interest and their literacy, because most of the 
subjects like mathematics, science and geography are taught in English. The language of instruction in Bhutan is English which students begin learning in about preprimary grade. All subjects (except for Dzongkha of course) are taught in English.

\section{DISTANCE EDUCATION IN BHUTAN}

Bhutan is a small, landlocked country in southern Asia, between China and India. Its population is 634,982 , and it covers 38,394 square kilometers. It has one of the world's smallest and least developed economies. Agriculture, forestry, and hydroelectric power provide the main sources of income for $90 \%$ of the population. International agencies are currently supporting a number of educational, social, and environmental programs. In 2003, the higher education sector in Bhutan was reorganized through the creation of the Royal University of Bhutan bringing together eight higher education institutes and two teacher education institutions, including the National Institute of Education (NIE) in Samtse, which is in the southern border of Bhutan with India. Recently, the NIE was renamed as Samtse College of Education and the Paro College of Education in the west. The Royal University of Bhutan, founded on $2^{\text {nd }}$ June, 2003 by a royal decree is the national university system of Bhutan. It was established to consolidate the management of tertiary education in Bhutan. It is a decentralized university with 10 constituent colleges spread across the kingdom. The 10 member colleges are:

- The College of Science and Technology in Rinchhending, Phuntsholing.

- The Gedu College of Business Studies in Gedu, Chukha.

- The National Institute of Traditional Medicine in Thimphu.

- The Institute of Language and Culture Studies in Simtokha, Thimphu.

- Sherubtse College in Kanglung, Trashigang.

- The Paro College of Education in Paro.

- The Samtse College of Education in Samtse.

- The Royal Institute of Health Sciences in Thimphu.

- The College of Natural Resources in Lobesa, Thimphu.

- The Jigme Namgyel Polytechnic in Dewathang, Samdrup Jongkhar.

The two teacher education colleges, Paro College of education in Paro and the Samtse College of education are the only two colleges which provide distance education for the up gradation of teachers who could not avail degree qualification due to some unavoidable reasons. The Paro College of Education in Bhutan is the pioneering institution that first introduced distance education in the country. It is continuing its pioneering work by introducing Information Communication Technology (ICT) as major support for its Distance Teacher Education Programme (DTEP), which allows certified teachers to receive Bachelor's degrees in primary teaching. The telecommunications sector in Bhutan is experiencing speedy growth and development, and it is clear that ICTs will become common tools in the delivery of educational services.

\section{PROGRAMMES DETAILS THROUGH DISTANCE MODE}

Bachelor of Education (Primary) is a four years course through mixed mode of distance learning and residential school. The award granting body is the Royal University of Bhutan. In acquiring Bachelors of Education through distance mode, the students do not have to pay any 
fees as it is rather an initiative taken by our government to upgrade and update our teachers for the future of Bhutan. The in-service teachers are paid travel allowance and daily allowance by the Royal Government of Bhutan when they attend their residential school twice a year. The main aims of the programme are to provide academic and professional development for the primary teachers to the B.Ed level, enhance competency and commitment of teachers to teach any class and any subject in the primary schools, improve desirable values and attitudes, and confidence to develop in the students under their charge as teachers, develop positive attitude towards the profession and its continued development while meeting the national needs and the aspiration in the light of the national education with changing environment.

For entry to the programme, the candidates must have a minimum of 10 years of teaching experience and should be presently teaching at one of the schools. The required documents are that the candidate must produce primary teacher's certificate and Mark sheet, Class XII or Diploma Certificate and mark sheet, recommendation from the supervisor and detailed Portfolio authenticated by supervisors. To register for this course, the applicant needs to fill in the In-service training application form of Ministry of Education and registration form for Inservice B.Ed Primary. The applicant is required to provide a valid security clearance certificate and audit clearance certificate.

\section{CURRICULUM IN DISTANCE EDUCATION PROGRAMME}

The programme contains 32 modules. In general, years 1 and 2 focus on lower primary modules and years 3 and 4 on upper primary modules with the opportunity in the $8^{\text {th }}$ semester to promote their knowledge concerning certain subjects, classroom skills, and related studies. All modules are theory-based with practical implementations, reasonably spread within the structure for sound and logical chaining from modules being built on learning developed in past modules. One module is equivalent to 12 academic credits. One unit of academic credit is equivalent to 10 hours of student effort. Hence, each module has 120 academic hours of learning time. Each module gets 10 hours of contact time in every semester during the residential school and $110 \mathrm{hrs}$ (120-10) of independent study time per module. The independent study time will be supported by self- instructional module materials, ICT such as Learning management system, email, telephone/mobile, fax etc. They offer three specialization subjects of English, Geography and History for the degree level. A student enrolled in the DE programme can choose one subject out of History, English, Geography or Science as their specialization subject based on his or her capabilities, teaching areas and interest. The electives refer to programmes that students wish to specialize in as their main subject for the degree. This model assumes that specialists, rather than 'class teachers' (who teach all primary subjects), are required in primary schools. Thus the DEP has modules that are compulsory and elective. The program comprises a wide variety of modules that focus on personal and professional development and specialization in selected subjects of the student's choice. The programme also includes functional informational technology to keep the candidates abreast with growing technology. The learning of content and pedagogy are equally emphasized. Consequently the B.Ed (P) by distance education can be thought of as presently comprising 34 modules of four broad areas of study. They are Professional development studies - seven modules, Personal development studies - ten modules, Subject of specialization (elective) -10 modules each and primary curriculum - seven modules. The distance education enrollees have limited choice for their subjects of specialization which are English, History, Geography or Science. Mathematics has not been offered yet as subjects of specialization. 


\section{TEACHING AND LEARNING MODES IN DISTANCE EDUCATION}

This mixed mode programme of face to face and distance learning course delivery helps the teachers who take the course to develop and enhance their competencies in terms of their knowledge of subject content; skilful in handling a variety of teaching situations and relate the theory to practice. The faculty experience of teaching online must be as effective and professionally beneficial as the face to face teaching experience (J. C. Moore, 2002). This mode of study is very suitable for the matured teachers as it provides them with the opportunity to relate and test the theories to practice in the Bhutanese classroom situations and schools. It also helps them to be continuing learners as teachers and update themselves with advancement and developments in the field of education. It also allows them to learn while working without affecting the limited pool of teachers in the schools. The distance learning course delivery intends to keep the learners engaged throughout the semester without affecting their daily work in schools.

This programme will allow in-service teachers to learn at their own conveniences while working at the same time. It will also make learning more meaningful and relevant by enabling teachers in the programme to try out immediately whatever they learn, thus directly contributing to the quality of teaching in schools. Upreti, D.C (1988) found that the majority of distance learners joining B.Ed through correspondence courses had graduated in humanities and social sciences with low percentage of marks at school and college levels. A positive connection between learners' characteristics and success in distance learning at B.Ed level was reported by Gautam, R (1990). The age of the teacher trainees in the distance mode ranged from 25 to 61 years in the study of Pugazhenthi, G. (1991). Also, a considerable number of students, both at the B.Ed and M.Ed levels, had the rural background. Education and training are ongoing necessities for a skilled workforce and business may use distance education as a setting for job training and delivery. Computer based training is one example. Simsonson et al, (2003) mention "(CBT is stand alone instruction that does not require interacting with a teacher."

The Residential School (RS) is an essential part of the DEP. It is mandatory for all distance education enrollees to attend the residential school for level. The RS is held in the months of December and January. The exact dates are confirmed each year well in advance. All the office formalities such as registration, allotment of student number, issue of modules books etc. are done during the RS. The objectives of the RS are to get the students and the lecturers to know each other, familiarize students with the College and the resources available at the College, orient students to various programme modules and related materials, get students to attend sessions on topics that require face-to-face instruction, allow students to do research activities in the library, collect study materials, discuss assignments and other problems related to programme modules and complete administrative formalities. In-service teachers are engaged throughout the RS; sessions, seminars, presentations and practical classes are conducted in accordance to the timetable. Minor course work components such as presentation, practical etc. are assessed by respective tutors during the RS. The learners are given opportunity to clarify doubts about assignments and module contents which they need to do during their independent study. Most of the sessions are used to discuss about the Self-Instructional Materials (SIM) and difficult concepts included in the modules. At the end the RS students are given an opportunity to provide feedback about their tutors, modules and RS as a whole. About $90 \%$ of the in-service teachers have expressed their satisfaction with the Residential School in the recent year.

The in-service teachers are expected to study the self-instructional materials (SIM) which contain Module Outline; learning outcomes, assessments task schedule and criteria and the 
content. They are also required to spend at least two hours a day studying the SIM during their independent study time. At the end of each unit or section of SIM a provision/activity to check the learners' self learning progression is provided and also it gives a basis to write assignments. It is further supplemented by the ICT based learning support for online discussion with their individual tutors. Most of the in-service teachers have now access to internet connectivity and Regional Study Centres for those students in remote schools. Due dates for submission of course work components are arranged in such a way to check their learning progression and demands students to study every day. The feedbacks and additional remarks are provided in their assignments and returned. Besides, students use email, telephone to clarify their doubts when required.

During the summer of 2005, Ortiz-Rodriguez, Telg. Irani, Roberts $8 \&$ Rhoades (2005) conducted a phenomenological study that examined college students' perspectives of distance education. Researchers focused on using perspectives of college students versus using the mostly used "positive view, consisting of a top-down approach based on questionnaires and scales". In their study, a single open-ended question was asked to a population of students enrolled in distance education. Three themes emerged: (a) quality, (b) feedback, and (c) communication. The survey distance education students considered these three elements to be the most critical in distance education programs in higher education. Distance Education programs must be high in quality and offering; timely and regular feedback remains primarily important to remote students and communication tools should be effective and user friendly. There is also an emphasis given on the use of technology. ICT based learning support focuses on the impact of ICT use on the quality and accessibility of learning support for distance learning. The DTEP is a programme that is designed to update and upgrade professional qualification of in-service primary school teachers in Bhutan. It is one of the few certified professional development programmes available to primary school teachers in Bhutan.

The learning support services for the DTEP have been viewed to be severely limited due to lack of effective and efficient means of communication. Recent developments in telecommunication, has made the use of ICT a viable option for providing distance learning support. The colleges have been fairly successful in implementing the ICT based learning support in the recent years. The in-service teachers' views on the ICT based learning support is found positive. Since its commencement of ICT based learning support technology in 2005 there has been increasing users. At the moment college has emphasized to use feature of Moodle such as - Online forum discussion, submission of assignments, announcement forum and online feedback system. Students are provided about 9 sessions in each RS to learn how to use ICT based learning support, especially the LMS (Moodle) during the RSs. The recent feedback of summer residential school (2010) from the in-service teachers suggests their commitment to use learning management system (Moodle). And they have been using the Moodle for submitting assignments and down load the recourses uploaded by the tutors concerned. The college has also used the feature to provide weekly activities such as reading for the week feature in the Moodle to facilitate interaction and support in the distance programme. Furthermore with increasing accessibility to internet connectivity and Regional Centres for those in the remote schools have enabled them to benefit from the ICT based learning support.

Recent developments in telecommunication, has made the use of ICT a viable option for providing distance learning support. Authored by Frank B. Raymond on the topic delivering distance education through technology, published in 2000. The research paper states that the recent developments in technology have provided educators with an extremely wide variety of electronic tools to assist them in achieving one of their primary objectives which is highlighted 
as the transmission of knowledge to others. One of the most important uses of these technologies in higher education has been their employment for the delivery of distance education.

The research paper also describes the types of technology available for the delivery of distance education (computer-assisted education systems, audio/video-mediated education systems, and computer-mediated education systems), and has documented the effectiveness of these tools. It also discusses the successful experience of the school that pioneered the use of technology to deliver distance in the discipline of social work. Assessment is an essential part of learning. The programme in the college is mainly assessed through two modes: Continuous assessment and end-of-semester examinations. Examinations are conducted at the end of each semester for all the modules taught during the semester that have examinations as part of assessment. The In-service candidates will sit for the same examination at the same time with the pre-service B.Ed (P) at the examination centers.

To pass a module a student must acquire a minimum of $50 \%$ overall including both the continuous assessment and semester end examination. In addition, students must obtain a minimum of $40 \%$ each in continuous assessment and semester end examinations. At the end of each level examination are conducted. The examination papers are usually submitted to the distance education office by the individual module lecturer after moderation in-order to make multiple copies a week ahead of the exam. The distance education office in consultation with the Exam Secretary does the seating arrangements and other necessary arrangements for the exams. At the end of each level, a progress report is made in terms of the marks obtained (percentage) in each module. Where grades are used, the following conversion is given below:

Table no. 1

\begin{tabular}{|c|c|c|}
\hline Grade & Meaning & Marks \\
\hline A & Distinction & 75 \& above \\
\hline B & First Division & $65-74.9$ \\
\hline C & Second Division & $55-64.9$ \\
\hline D & Pass & $40-54.9$ \\
\hline E & Fail & 39.9 \& below \\
\hline
\end{tabular}

There is a need to admit more candidates to the programme as the country is still facing acute shortage of qualified teachers especially at the primary level. Currently there are approximately 1400 PTC teachers, who seek to upgrade their qualification. This is very evident from the increasing pressure for admission into the programme. 
Table no. 2

The annual enrolment projection for 2010 to 2012 .

\begin{tabular}{|c|c|c|c|c|}
\hline Year & $\mathbf{2 0 1 0}$ & $\mathbf{2 0 1 1}$ & $\mathbf{2 0 1 2}$ & $\mathbf{2 0 1 3}$ \\
\hline Year I & 90 & 90 & 90 & 90 \\
\hline Year II & 90 & 90 & 90 & 90 \\
\hline Year III & 90 & 90 & 90 & 90 \\
\hline Year IV & 90 & 90 & 90 & 90 \\
\hline Total & 360 & 360 & 360 & 360 \\
\hline
\end{tabular}

Courtesy: Paro College of Education

It is generally acknowledged that introducing technology is far easier than changing pedagogy. This applies to the higher education scene in Bhutan where landline technology is particularly problematic due to the mountainous terrain. Nevertheless, mobile and satellite technology can leapfrog over traditional solutions and offer some speedy wins' in the country, as they have in other developing countries. Media such as videoconferencing which do not disturb existing attitudes to teaching and learning are probably going to be the most acceptable in the short term at least. Introducing elements of resource-based and student-centred learning for students, however, may be the way forward to taking advantage of the best aspects of flexible learning.

\section{CONCLUSION}

Education enhancement plays an important role for the development of an economy. Distance education also is an educative process where you can attain higher education depending upon the learners' own effort to study whenever they can find time to do so. We consider that correspondence or home-study courses provide the right answer for these situations. The Distance education programme for in-service teachers in Bhutan provides an opportunity to upgrade and update their knowledge so that they can proceed and be confident in their profession. Distance education is a self paced learning which reduces stress and increases satisfaction. Although distance education is new concept in educational system but it has been catching up very fast in all countries and its importance is been realized all over the world and certainly in developing countries. The public have come to realize the place of distance education in their lives. It is one of the few accredited professional development programmes available to primary school teachers in Bhutan. The learning support services for the distance teacher education programme have been viewed to be severely limited due to lack of effective and efficient means of communication. Distance education is the most preferred medium of education today. Teachers who have landed in teaching profession without higher qualification opt to enroll in it to grow their career. 


\section{References}

[1] Birnbaum B. W. (2001). Foundations and Practices in the Use of Distance Education. Mellen studies in education, (Vol. 66, pp. 1-174). Lewiston: The Edwin Mellen Press.

[2] Dominguez B. (2001). Learner's Perception on Distance Education. Dissertation Abstract International 48(2), 46-48.

[3] Jamtsho S., Bullen M. (2007). Distance Education in Bhutan: Improving Access and Quality through ICT Use. Distance Education, 28 (2), 149-161.

[4] Jamtso S (1998). Handbook, Distance Education Programme, National Institute of Education, Paro: KMT Press, Bhutan.

[5] Keegan D. (1997). Foundation of Distance Education ( $3^{\text {rd }}$ Ed. J. London: Routledge, 2 , pp. 50-135.

[6] Maxwell T. Laird, D., Namgay Reid J., Laird J., Gyamtso D. (2006). Focus on student learning outcomes: Report of the Review of the Bachelor of Education (Primary) in Distance Education Mode In-service Programme. Report submitted to Samtse College of Education, Bhutan.

[7] Mehrotra C. M., Hollister C. D., McGahey L. (2001). Distance Learning: Principles for effective design delivery and evaluation. Thousand Oaks, CA: Sage Publications, Inc.

[8] National Institute of Education (1998). A Brief Guides for Module Writers, Distance Education Unit (NIE), NIE, Paro, Bhutan.

[9] National Institute of Education (2003). ICT Supported Distance Teacher Education in Bhutan to Enhance Learning Support and Access (Project Report). Ottawa, Canada: International Development Research Centre.

[10] Royal Government of Bhutan (1999). Bhutan 2020- A Vision for Peace, Prosperity and Happiness. Planning Commission, RGOB, Thimphu

[11] Royal University of Bhutan (2005). Strategic Plan, Draft July, 2005. RUB 2006 The Wheel of Academic Law, RUB: Semtoka, Bhutan. 